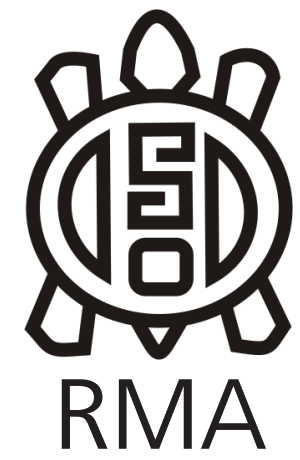

Arqueología

\title{
Arte rupestre y elecciones tecnológicas durante la transición hacia la producción de alimentos en la Puna Meridional Argentina (ca. 5.500-1.500 AP)
}

\author{
Rock art and technological choices during the transition towards food \\ production in Argentine Southern Puna (ca. 5.500-1.500 BP)
}

Matías Lepori

Instituto de Arqueología y Museo, Facultad de Ciencias Naturales e Instituto Miguel Lillo, Universidad Nacional de Tucumán, Argentina. E-mail: matu.lepori@gmail.com

\begin{abstract}
Resumen
El trabajo aquí presentado analiza los cambios observados en las elecciones vinculadas con la producción rupestre, buscando interpretar tales modificaciones dentro del marco de un proceso socio-histórico más amplio, la transición hacia la producción de alimentos. Con esa finalidad en mente se trabajó con la totalidad de sitios y motivos correspondientes a esa temporalidad ubicados en la microrregión de Antofagasta de la Sierra, Catamarca. De esta manera pudimos definir que ciertos factores de cambio, considerados relevantes para la investigación de modificaciones en otras esferas del accionar social durante este mismo momento, también desempeñaron un rol en la producción del arte rupestre. Sin embargo, y más importante aún, fue la consideración de las técnicas de producción utilizadas, el análisis de distintas variables sobre sitios y motivos (características de emplazamiento, visibilidad, tipos de soporte, modalidades estilísticas, tipos y cuantificación de motivos) y su evaluación dentro de un contexto más amplio lo que nos permitió interpretar de manera más ajustada las tendencias apreciadas en el largo plazo. Consideramos este trabajo como un primer acercamiento a una problemática que hasta este momento sólo fue abordada de manera tangencial, destacando el carácter novedoso, aunque preliminar, de la propuesta.
\end{abstract}

Palabras Clave: Arte Rupestre; Transición; Técnicas de Producción; Elecciones; Puna Argentina

\begin{abstract}
This paper analyzes the changes observed in the choices related to rock art production, seeking to interpret those modifications within the frame of a broader socio-historical process, the transition to food production. With that goal in mind, we worked with the totality of archaeological sites and rock art motifs corresponding to such temporality located in the micro-region of Antofagasta de la Sierra, Catamarca. In this way, we were able to define that certain change factors, considered important for the research of modifications in different social action spheres during this same lapse, also played a relevant role in rock art production. Nevertheless, and more importantly, it was the consideration of the used rock art production techniques, the analysis of different variables both at a site and motif level (emplacement and visibility characteristics, stylistic modalities, types of surfaces, classes and quantities of motifs), and their examination within a broader context which allowed us to perform a more adjusted interpretation of the observed long term trends. We think in this paper as a first approach towards a problematic that, so far, has only been addressed tangentially, highlighting the novel, yet preliminary character, of this proposal.
\end{abstract}

Keywords: Rock Art; Transition; Production Techniques; Choices; Argentine Puna

Las evidencias arqueológicas recuperadas en Antofagasta de la Sierra (en adelante ANS) durante más de 30 años de investigaciones sistemáticas, remiten a un espacio utilizado de manera ininterrumpida al menos desde el Pleistoceno Final (Martínez et al. 2010). Sin embargo, un rasgo característico de la extensa ocupación humana en la microrregión (sensu Aschero, 1988) de ANS, es que los diferentes cambios acontecidos allí se enmarcan en "una continuidad en la transmisión generacional de información y prácticas de hacer a través del tiempo" (Aschero y Hocsman, 2011: 394).
De esta manera, el lapso que nos propusimos investigar es uno de nexo entre dos formas de ser y hacer, entre grupos cazadores-recolectores y grupos agrícolapastoriles, caracterizado conceptualmente en la bibliografía tradicional como un proceso de transición hacia la producción de alimentos evidenciada desde la domesticación animal y vegetal (Babot, 2004; Reigadas, 2000-2002, entre otros). Sin embargo, más allá de que el foco de las investigaciones generalmente haya estado puesto sobre los rasgos económicos de dicha transición (de allí su denominación), diversas esferas del accionar 
social también vieron modificadas sus bases durante estos momentos. El arte rupestre, por supuesto, no se mantuvo al margen de esta tendencia.

Esta afirmación nos permite abordar la investigación del proceso transicional hacia la producción de alimentos desde una perspectiva en donde prime el entender a las modificaciones como cambios en la continuidad, donde las sociedades cazadoras-recolectoras se constituyen en antecedentes para la caracterización y la conformación de las sociedades agro-pastoriles posteriores (Aschero y Hocsman, 2011; Hocsman, 2006).

La microrregión de Antofagasta de la Sierra, sector integrante de la llamada Puna Salada (Santoro y Núñez, 1987), constituye un desierto de altura con altitudes medias oscilando entre los 3.600 y 3.800 msnm. Presenta como elemento destacado del paisaje el sistema hídrico de los ríos Calalaste-Toconquis-Punilla/Antofagasta y sus afluentes, dentro de los cuales se destacan los ríos Las Pitas y Miriguaca. Estos cursos de agua dan lugar a vegas y ambientes relativamente aptos para el desarrollo de poblaciones humanas.

Los sitios analizados se encuentran emplazados en diferentes sectores altitudinales, cada uno de ellos con características particulares que fueron aprovechadas para la realización de diversas prácticas socio-económicas (Olivera, 1998). Definidos por Olivera (1992), dichos sectores son el Fondo de Cuenca (entre $3.400 \mathrm{y}$ 3.550 msnm conforman el microambiente de mayor potencialidad para el desarrollo agrícola), los Sectores Intermedios (entre 3.550 y 3.800 msnm, habrían permitido el desarrollo de cultivos a baja escala) y las Quebradas de Altura (por encima de los 3.800 msnm, se trata del sector más vinculado a la actividad de la caza y el pastoreo temporario).

En este trabajo analizamos los cambios registrados en las técnicas de producción del arte rupestre y cómo éstos se relacionaron con el proceso transicional. Apelamos a un criterio de análisis contextual amplio en donde se tengan en consideración no sólo los cambios propios del arte rupestre sino también los de la sociedad en su conjunto y que terminan incidiendo de una u otra manera sobre la práctica rupestre.

Es importante mencionar que una de las particularidades de muchos sitios rupestres en ANS es el hecho de que presentan una recursividad en su uso a lo largo del tiempo, pudiendo hallarse en un mismo sitio motivos correspondientes a diferentes momentos (Martel et al., 2012). Teniendo esto en mente, el presente trabajo se focaliza en la presentación y discusión del repertorio rupestre correspondiente a tres modalidades estilísticas, de las siete definidas para la microrregión, (Aschero, 1999) que se corresponden cronológicamente con el proceso de transición hacia la producción de alimentos (Aschero y Hocsman, 2011).
Dado que las investigaciones sobre el arte rupestre de ANS siempre han estado más vinculadas con enfoques ligados a la adscripción estilística (Aschero, 1999; Aschero y Martel, 2003-2055; Martel et al., 2012, entre otros) y a la vinculación de los contextos socio-culturales con la significación de los temas y motivos representados (Aschero, 2006; Aschero et al., 2006, 2009, entre otros), consideramos más que necesaria una re-evaluación de la información ya disponible y la generación de nuevos datos bajo la luz de otros enfoques teórico-metodológicos propuestos en los últimos años tendientes a abordar el trasfondo de las elecciones realizadas por los grupos productores al momento de plasmar las representaciones rupestres (Fiore, 2006, 2007).

Dentro de las observaciones realizadas sobre el arte rupestre de la microrregión ya se había insinuado una tendencia general hacia la disminución de motivos pintados y el consecuente aumento de motivos grabados durante este periodo pero, no obstante, esta situación nunca había sido problematizada per se (Aschero, 2006, 2009). Es así que nos propusimos identificar los factores que actuaron como condicionantes (tanto positivos/posibilidades como negativos/limitantes) de las elecciones técnicas vinculadas con la producción de arte rupestre durante este lapso de aproximadamente 4.000 años, relacionándolos con las situaciones contextuales cambiantes y los nuevos requerimientos, desafíos y limitaciones que éstas iban generando.

\section{Antecedentes}

El estudio del arte rupestre es una de las líneas de trabajo que cuenta con mayor desarrollo dentro de las temáticas abordadas por los investigadores de ANS, resultando en numerosos análisis e investigaciones que abarcan los diferentes periodos de la arqueología local, lo cual ha generado un significativo volumen de datos contextuales que funcionan como una base general sobre la cual se hace posible incursionar en nuevos problemas e interrogantes.

En general, las investigaciones sobre el arte rupestre de ANS han estado apuntadas a la resolución de tres tipos de problemáticas: cronología, producción y significación. La primera ha servido como marco para la definición de siete modalidades estilísticas para la secuencia ocupacional de la microrregión (Aschero, 1999), de las cuales tres corresponden al proceso transicional y conforman el objeto de estudio del presente trabajo. Por otra parte, los conceptos definidos originalmente por Aschero (1988) como contexto funcional de la ejecución y contexto temático de la representación son los que han guiado las investigaciones enfocadas en la interpretación del arte rupestre en sí.

El análisis y la re-lectura de diversos trabajos (Aschero, 1999, 2006; Aschero y Podestá, 1986; Martel y Escola, 2011; Podestá, 1986-1987, entre otros) nos permitió 
definir un problema de investigación que, muchas veces insinuado, nunca había sido abordado. Nos referimos al de la elección diferencial de técnicas de ejecución en el arte rupestre a través del tiempo y a los procesos sociohistóricos que sirvieron como marco contextual para tales prácticas. Así, el paulatino descenso de la producción de motivos pintados y el consecuente aumento de motivos grabados es el problema que buscamos (comenzar a) analizar, discutir e interpretar.

En concreto buscamos abordar nuestro trabajo en relación a tres modalidades estilísticas cuya cronología coincide con el proceso transicional (Aschero, 1999; Aschero y Hocsman, 2011): modalidad Quebrada Seca (mQS, ca. 5.500-3.800 AP), modalidad Río Punilla (mRP, ca 3.800-2.500 AP) y modalidad Peñas Coloradas (mPC, ca. 2.500-1.700 AP).

La transición hacia la producción de alimentos y el arte rupestre

Los estudios de los momentos transicionales, abordados desde distintos tipos de materiales y líneas teóricometodológicas, han demostrados ser sumamente significativos dentro de la reconstrucción general de los procesos socio-culturales (Aschero, 2006; Aschero y Hocsman, 2011; Babot, 2014; Cremonte et al., 2010; Hocsman, 2006, 2010; Hocsman y Babot, 2018; Núñez y Santoro, 2011; Oliszewski et al., 2018; Vergara y Troncoso, 2015; entre otros). Los procesos transicionales implican grandes e importantes cambios tanto en la estructura como en la organización de los grupos humanos que los vivieron, y se postula que estas transiciones o cambios pueden darse de manera repentina o gradual, pudiendo responder a estímulos provenientes de "áreas nucleares" (Lavallée, 2006) o a cambios originados en el seno de los grupos involucrados (Aschero y Hocsman, 2011; Núñez, 1994; Núñez et al., 2006) respectivamente. Aquí concordamos con la segunda propuesta, basándonos en evidencias que muestran una continuidad generacional en el uso de los espacios y una transferencia directa en lo que respecta a conocimientos técnicos y manejo/obtención de recursos (Aschero y Hocsman, 2011; Aschero y Martínez, 2001; Hocsman, 2002, 2006; Hocsman et al., 2012; Pintar, 2014, entre otros).

La transición dentro de la cual se encuadra nuestra investigación es, de acuerdo a su concepción original, una de carácter económico ligada al proceso domesticatorio (Aschero, 1996; Hocsman, 2002). Cabe destacar, sin embargo, que en los últimos años se han consolidado posiciones que abordan al proceso transicional desde diferentes esferas del accionar social como veremos más adelante. Es así que los grupos antofagasteños transitaron, en un periodo de aproximadamente 4.000 años, desde una estrategia económica netamente extractiva (la caza y la recolección) hacia una productiva (agro-pastoralismo), con situaciones mixtas, propiamente transicionales, en las cuales se conjugaron ambos tipos de prácticas (Escola, 2002; Olivera, 1992, 1998).

La información proveniente de diferentes sitios, materiales, asociaciones contextuales y temporalidades nos llevó a sintetizar la secuencia socio-económica para ANS de la manera observada en la Tabla 1 (Aschero et al., 2014; Babot, 2009, 2011, 2014; Hocsman, 2007; Olivera, 1998; Reigadas, 2000-2002; Urquiza y Aschero, 2014, entre otros).

Sin embargo, y como veremos a continuación, el proceso transicional también ha sido analizado desde los cambios ocurridos en otras esferas de la acción social como: las maneras particulares de ocupar en el espacio, las interacciones sociales, el manejo de recursos vegetales y las elecciones tecnológicas relacionadas con la manufactura lítica, por citar algunos ejemplos (Aschero y Hocsman, 2011; Babot, 2009; Cremonte et al., 2010; Escola et al., 2013; Hocsman, 2002, 2006; Núñez et al., 2006; Nuñez y Santoro, 2011; Yacobaccio, 2001, entre otros).

En lo que respecta a los patrones de ocupación del espacio en ANS, durante el proceso transicional comienzan a utilizarse espacios acondicionados y/o equipamiento de sitio, sumado a cambios en la organización interna de los sitios a partir del 5.500 AP (Aschero y Hocsman, 2011). Esto se relaciona con una tendencia hacia una disminución en la movilidad residencial pero que no tuvo incidencia sobre la mantención y el fortalecimiento de la macromovilidad o redes de interacción (sensu Lazzari, 1999) a largas distancias (Hocsman, 2002, 2006).

La fijación de los grupos humanos al paisaje como consecuencia de la menor movilidad residencial y el aumento poblacional habrían tenido como consecuencia

Tabla 1. Modelos de sistemas de subsistencia y su desarrollo en el tiempo en la microrregión de ANS.

Table 1. Models of subsistence systems and their development through time in the micro-region of ANS.

\begin{tabular}{lcccc}
\hline Temporalidad & $\begin{array}{c}\text { ca. } 10.000- \\
5.000 \mathrm{AP}\end{array}$ & ca. $4.700-3.600 \mathrm{AP}$ & $c a .3 .600-2.100 \mathrm{AP}$ & ca. 2.100 AP en adelante \\
\hline Subsistencia & $\begin{array}{c}\text { Economía } \\
\text { extractiva }\end{array}$ & $\begin{array}{c}\text { Economía extractiva + producción a } \\
\text { bajo nivel sin domesticados }\end{array}$ & $\begin{array}{c}\text { Economía extractiva + producción a bajo } \\
\text { nivel con domesticados }\end{array} \quad \begin{array}{c}\text { Economía productiva + recursos } \\
\text { provenientes de prácticas extractivas }\end{array}$
\end{tabular}


situaciones de territorialidad y competencia por los espacios. Para estos momentos, la territorialidad aún no implica la aparición de desigualdad social o de jerarquías (más allá de posibles roles de liderazgo temporales), pero se expresa a través de un incremento en la presencia de marcas territoriales (arte rupestre en vinculación a ofrendas y/o enterratorios) y en el acceso diferencial a ciertos recursos líticos durante el lapso ca. 4.100-3.400 AP (Aschero, 2006; Aschero y Hocsman, 2011; Hocsman, 2006).

A pesar de que el eje de esta investigación sea la producción rupestre, las demás esferas mencionadas con anterioridad son igualmente importantes en el encuadre que pretendemos para el estudio de esta materialidad, dentro de lo que se denomina la "socialización del arte rupestre" (Aschero, 1983-1985). Consideramos así a las representaciones rupestres como un producto material más de la actividad humana, razón por la cual se hace necesario relacionar la producción de pinturas y grabados rupestres con otras actividades realizadas por el grupo productor, entendiendo a éstas no como

Tabla 2. Síntesis de las modalidades estilíisticas presentes en ANS y sus rasgos definitorios.

Table 2. Synthesis of the stylistic modalities found in ANS and their main features.

\begin{tabular}{|c|c|c|}
\hline Modalidad Estilistica & $\begin{array}{l}\text { Bloque } \\
\text { Temporal }\end{array}$ & Particularidades \\
\hline Punta de la Peña (mPP) & $\begin{array}{l}\text { ca. } 9.000- \\
5.500 \mathrm{AP}\end{array}$ & Signos geométricos-abstractos simples. \\
\hline Quebrada Seca (mQS) & $\begin{array}{l}\text { ca. } 5.500- \\
3.800 \mathrm{AP}\end{array}$ & $\begin{array}{l}\text { Mantiene lo presente en mPP pero agrega componentes no- } \\
\text { figurativos y figurativos, humanos y animales. }\end{array}$ \\
\hline Río Punilla (mRP) & $\begin{array}{l}\text { ca. } 3.800- \\
2.500 \mathrm{AP}\end{array}$ & $\begin{array}{l}\text { Énfasis en la representación de camélidos, asociación con } \\
\text { figuras humanas, camélidos bi- y tri- cápites. }\end{array}$ \\
\hline Peñas Coloradas (mPC) & $\begin{array}{l}\text { ca. } 2.500- \\
1.700 \mathrm{AP}\end{array}$ & $\begin{array}{l}\text { Preponderancia de la figura humana, figuras esquemáticas y } \\
\text { geométricas de camélidos, máscaras. }\end{array}$ \\
\hline Peñas Chicas (mPCh) & $\begin{array}{l}\text { ca. } 1.700- \\
1.500 \mathrm{AP}\end{array}$ & $\begin{array}{l}\text { Figuras humanas armadas y escenas de lucha, antecedentes de } \\
\text { maquetas. }\end{array}$ \\
\hline $\begin{array}{l}\text { Punta del Pueblo } \\
\text { (mPdP) }\end{array}$ & $\begin{array}{l}\text { ca. } 1.500- \\
1.000 \mathrm{AP}\end{array}$ & $\begin{array}{l}\text { Camélidos de contorno abierto, mascariformes con ojos } \\
\text { rasgados, rastros de pisadas humanas. }\end{array}$ \\
\hline $\begin{array}{l}\text { Confluencia y } \\
\text { Derrumbes (mCfyD) }\end{array}$ & $\begin{array}{l}\text { ca. } 1.000-550 \\
\mathrm{AP}\end{array}$ & Maquetas complejas, camélidos con carga, escutiformes. \\
\hline
\end{tabular}

factores que determinaron la producción rupestre sino como elementos involucrados en un proceso de retroalimentación (Álvarez y Fiore, 1995; Fiore, 2007, 2009; Méndez Melgar, 2007).

De esta manera, es importante en primer lugar conocer la secuencia cronológica propuesta para el arte rupestre de la microrregión, para luego realizar comparaciones entre las situaciones observadas e interpretadas en relación a esta materialidad y la información contextual amplia disponible para esos momentos, generada desde otras vías de análisis. Las investigaciones de Aschero (1999, 2006) principalmente, así como las contribuciones realizadas por otros investigadores trabajando en la microrregión (Aschero et al., 2006, 2009; Martel, 2006; Martel et al., 2012, entre otros) permitieron definir 7 modalidades estilísticas que abarcan más de 9.000 años de ocupación en ANS (Tabla 2). Cabe destacar que los criterios seguidos para el ordenamiento cronológico fueron principalmente estilísticos, aunque debidamente complementados por dataciones directas (pigmentos desprendidos hallados en estratigrafía) e indirectas (principalmente superposiciones y asociaciones) de los motivos rupestres. Como ya dijimos anteriormente, tres de estas modalidades son las que se relacionan con el proceso transicional hacia la producción de alimentos y serán analizadas en este trabajo.

\section{Metodología de trabajo}

Para poder acercarnos a realizar interpretaciones que vinculen la situación del arte rupestre con el resto de las esferas del accionar social, primero debíamos conocer en profundidad y en detalle cuestiones referentes a las elecciones técnicas plasmadas por los productores de arte rupestre de ANS. Por ello decidimos trabajar con la totalidad de sitios ( $\mathrm{N}=22$ ) con presencia de motivos rupestres $(\mathrm{N}=745)$ asignables a las tres modalidades que aquí nos conciernen (Figura 1). En la Tabla 3 presentamos una síntesis de los sitios analizados, sus emplazamientos y el conteo de motivos en cada uno de ellos, discutiendo con mayor profundidad algunos aspectos en los siguientes apartados.

En pos de acceder a un análisis contextual lo más amplio posible en relación a las representaciones rupestres y las elecciones que llevaron a su manufactura, recurrimos al concepto de "caja de herramientas" (sensu Deleuze en Foucault 2001) para justificar la utilización de criterios teóricos cuya combinación podría haber sido calificada, a priori, como incompatible. Lejos de serlo, la consideración de estos criterios teóricos y su evaluación en relación a cada modalidad 


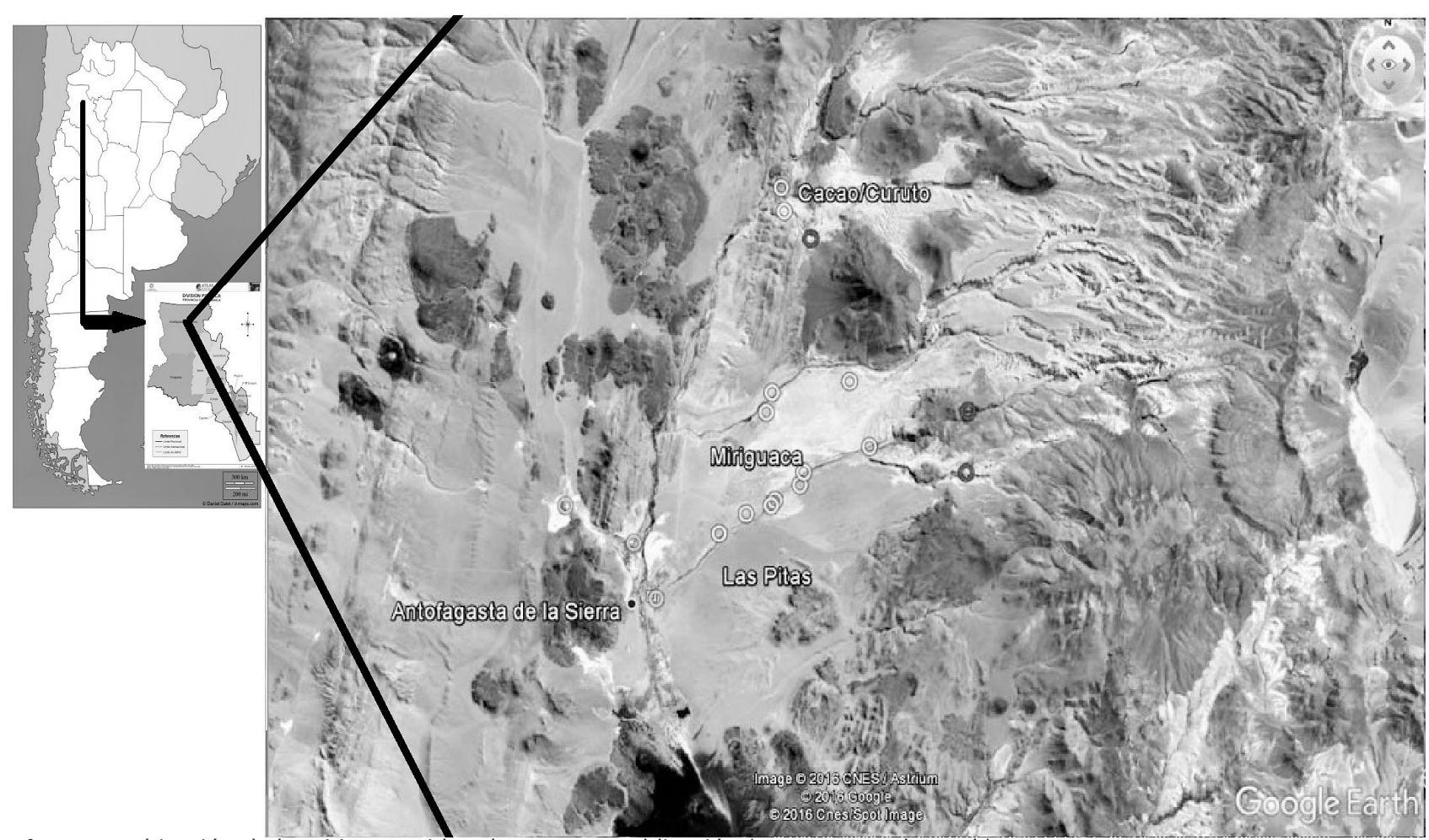

Figura 1. Ubicación de los sitios considerados en esta publicación (Fuente: Google Earth).

Figure 1. Location of the analyzed sites in this paper (Source: Google Earth).

estilística nos permitió realizar un abordaje de amplio espectro del problema.

Así, nuestra caja de herramientas se nutrió de conceptos tales como: contexto de producción y significación del arte rupestre (Aschero 1988), estilo y modalidades estilísticas (Aschero 1999), costos económicos (Fiore 2006, 2007), ideología/cosmovisión (Barnard 2001; Berenguer 1995), elecciones tecnológicas (Lemonnier 1986; Pfaffenberger 1992) y emplazamiento (Gallardo 2001, 2004; Gallardo et al. 1999; Martel 2009). Su articulación en el proceso analítico e interpretativo nos permitió afrontar esa mirada más amplia del problema.

En lo que respecta a la consideración de los costos económicos de la producción de pinturas y grabados rupestres, hemos seguido los lineamientos de Fiore (2006) estableciendo una línea de base que nos permita comparar ambas técnicas de producción en relación a los contextos de producción cambiantes, como veremos en el desarrollo de este artículo. Esta autora propone abordar cuatro factores que pudieron haber influido en los costos de producción de las representaciones rupestres, a saber: la disponibilidad de materias primas, la dureza de los soportes, la cantidad de cadenas operativas implicadas y la perdurabilidad relativa de ambas técnicas.

Ciertamente, estos factores no habrían sido los únicos que se encontraban operando sobre la creación del arte rupestre, pero es importante tenerlos en consideración ya que pueden ser evaluados en relación a las dinámicas sociales generales del grupo humano en cuestión y las modificaciones específicas que caracterizan al proceso transicional en ANS.

Consideramos para este trabajo dos fuentes diferentes de información. Por un lado, la generación directa de datos basada en el trabajo de campo y laboratorio. Por el otro, recurrimos a la recopilación de datos ya publicados y su consecuente revisión y re-evaluación de acuerdo a propuestas estilísticas más modernas generadas para la microrregión.

Toda esta información fue volcada en una planilla estandarizada y diseñada para tales fines, en la cual se consignan un total de 10 variables relevantes para la investigación:

- Nombre y sigla del Sitio (por ejemplo, Alero Sin Cabeza - ASC)

- Características del Sitio (por ejemplo, margen SE de la Vega de Real Grande)

- Localidad Arqueológica (por ejemplo, Paicuqui)

-Tipo de Soporte (Alero, Farallón, Bloque Suelto, Cueva, Parapeto)

-Emplazamiento (Fondo de Cuenca, Sectores Intermedios, Quebradas de Altura)

- Visibilidad (Alta/Baja, Arte Público/Arte Privado)

- Modalidad Estilística (mQS, mRP, mPC)

- Clase de motivo (Signo lineal, Signo circular, Figura Felínica, Camélidos en escenas, etc.) 
- Tipo de Motivo (Figurativo, No Figurativo, Indeterminado) - Cantidad de Motivos (Pintados y Grabados)

Adicionalmente, la planilla también fue utilizada para la generación de una base de datos que pueda ir ampliándose con el paso del tiempo, razón por la cual también se consignaron fechados y sitios asociados, así como las fuentes bibliográficas en el caso que las hubiera.

Cabe mencionar que el análisis de visibilidad de los sitios y motivos rupestres se realizó siguiendo los lineamientos planteados por Criado Boado (1993) teniendo en cuenta principalmente dos categorías: dimensiones de los motivos y posición de los soportes en relación al entorno. Esta clasificación fue utilizada posteriormente para ordenar a los sitios de acuerdo a un arte público o privado (sensu Schaafsma 1985), a un nivel general que permitiera su ordenamiento en categorías binarias fácilmente comparables, al menos en esta etapa de la investigación. Para la adscripción de los motivos según clases se siguieron los postulados de Aschero (2006) con el objetivo de contar con un sistema de clasificación homogéneo y comparable.

Estos datos fueron posteriormente trabajados recurriendo a análisis comparativos cuali- y cuantitativos ajustados para observar el comportamiento a lo largo del tiempo de los motivos rupestres en relación a diferentes variables, lo cual nos permitió generar una serie de gráficos que resultan útiles para la etapa de interpretación y para presentar los resultados de manera visualmente más amigable'

\section{Resultados}

A continuación presentamos los resultados cuantitativos obtenidos, intentando vincular esta información con otras líneas de evidencias en pos de contextualizar esta materialidad, el arte rupestre, dentro del panorama social más amplio. Para ellos recurriremos a una presentación individual de la situación durante cada modalidad estilística para posteriormente, en las conclusiones, realizar una síntesis detallando las tendencias más generales a largo plazo.

\section{Modalidad Quebrada Seca}

Vinculada a los momentos iniciales del proceso transicional hacia la producción de alimentos, los motivos correspondientes a esta modalidad estilística representan el $18.93 \%$ del total de la muestra analizada $(\mathrm{N}=141)$ y pueden ser hallados en 10 de los 22 sitios considerados. Observamos una elevada representación de motivos no figurativos (73.05\%, N=103) que está en concordancia con lo que serían las expresiones rupestres de grupos cazadores-recolectores (Aschero 1999), aunque no

${ }^{1}$ Por motivos de espacio no se incluyen aquí la totalidad de gráficos generados sino sólo aquellos que representan una síntesis más acabada. debemos dejar de mencionar el hecho de que la mQS es la primera dentro de la secuencia microrregional en contar con motivos figurativos $(9.93 \%, \mathrm{~N}=14)$, principalmente zoomorfos.

Se observa una muy clara tendencia hacia la elección de la técnica de la pintura $(81.56 \%, N=115)$ por sobre el grabado (18.44\%, $\mathrm{N}=26)$. Cabe mencionar que la modalidad estilística precedente sólo cuenta con representaciones pintadas (Aschero y Podestá 1986), por lo que podemos hablar de la técnica del grabado como una innovación tecnológica propia de estos momentos. Aunque la producción de pinturas rupestres puede ser considerada como más "costosa" que la de grabados (ver más abajo), consideramos que las formas de hacer tradicionales (entendiendo por "tradicionales" a las vinculadas con los modos de vida anteriores a estos momentos) jugaron un rol fundamental en la elección tecnológica durante estos momentos.

Estos factores, vinculados con el mantenimiento de prácticas tradicionales, también pueden apreciarse en lo que respecta a la elección de emplazamientos, donde observamos una marcada preferencia por la utilización de espacios emplazados en el sector de las Quebradas de Altura (61.7\%, $\mathrm{N}=87$ ), quedando relegados en la consideración los Sectores Intermedios (33.33\%, N=47) y el Fondo de Cuenca (4.97\%, N=7). Sostenemos esta vinculación debido a la búsqueda intencional de espacios en las proximidades de lugares con alto potencial para la caza y el pastoreo, situación que llevó a que Aschero (2006) planteara una posible funcionalidad del arte rupestre como demarcador de espacios de retorno previsto dentro de la circulación de los grupos humanos.

La elección de emplazamientos no se limita a estas observaciones generales de la ubicación de los sitios dentro del paisaje de la microrregión, sino que también busca aproximarse a entender la vinculación entre espacio y mensaje a través del análisis de otro factor. Nos referimos a la elección de espacios reparados o expuestos y su relación con un arte de carácter más o menos público (sensu Schaafsma 1985). Así, a pesar de utilizar ambos tipos de espacios, el arte de la mQS se caracteriza por una marcada predominancia de la elección de espacios de acceso visual restringido, siendo que un $85.52 \%$ de los motivos correspondientes a esta modalidad estilística (124 de 145) han sido realizados allí.

Nos interesa destacar que las diversas observaciones realizadas en cuanto a cómo, dónde y qué era reproducido a través de las expresiones rupestres de la mQS nos remite a un arte de carácter privado (sin que ello signifique restringido) mediado por la ideología del grupo productor y el tipo de información a transmitir.

\section{Modalidad Río Punilla}

La modalidad estilística Río Punilla, que ha sido definida y 
contextualizada dentro del proceso transicional abordado, presenta ciertas características que, comparándolas con las de la modalidad precedente y la subsiguiente, se muestran transicionales en sí mismas (Aschero 2006). El $29.93 \%$ de los motivos analizados en la muestra total $(\mathrm{N}=223)$ fueron adscritos a esta modalidad estilística y se documentó su presencia en 8 de los 22 sitios que componen la muestra (36.36\%). En lo que respecta a la elección de elementos a ser representados la tendencia se revierte durante este lapso, siendo los porcentajes de motivos figurativos y no figurativos (más indeterminados ${ }^{2}$ ) $68 \%$ y $32 \%$ respectivamente.

En lo que respecta a la elección de emplazamientos para la realización del arte rupestre de la mRP, los números indican que en las Quebradas de Altura se ejecutaron un $32.28 \%(\mathrm{~N}=72)$ del total de motivos correspondientes a esta modalidad, mientras que los Sectores Intermedios agrupan un $47,08 \%(\mathrm{~N}=105)$ y el Fondo de Cuenca un $20.63 \%(\mathrm{~N}=46)$. De esta manera, el lapso correspondiente a esta modalidad estilística es el más equitativo en relación a la ocupación del espacio, lo cual puede estar respondiendo a diferentes necesidades y actividades que implicaban un uso diversificado del espacio debido, por ejemplo, a la convivencia de la caza y la recolección con las actividades domesticatorias y productivas (Aschero y Hocsman 2011), aunque ya con una intencionalidad de ocupar los sectores más apropiados para la producción agrícola-pastoril (Martel 2006; Olivera y Podestá 1993).

Es interesante analizar los números que arroja la cuantificación de las técnicas de producción utilizadas durante este momento, ya que la mRP cuenta con $60.09 \%$ $(\mathrm{N}=134)$ de motivos pintados y $39.91 \%(\mathrm{~N}=89)$ de motivos grabados. Estos resultados ejemplifican un fuerte avance

'La clasificación de un motivo como indeterminado puede deberse a una mala conservación que no permita distinguir la forma original o una morfología que no permiten adscribirlos a ninguna categoría establecida (Aschero com. pers.).

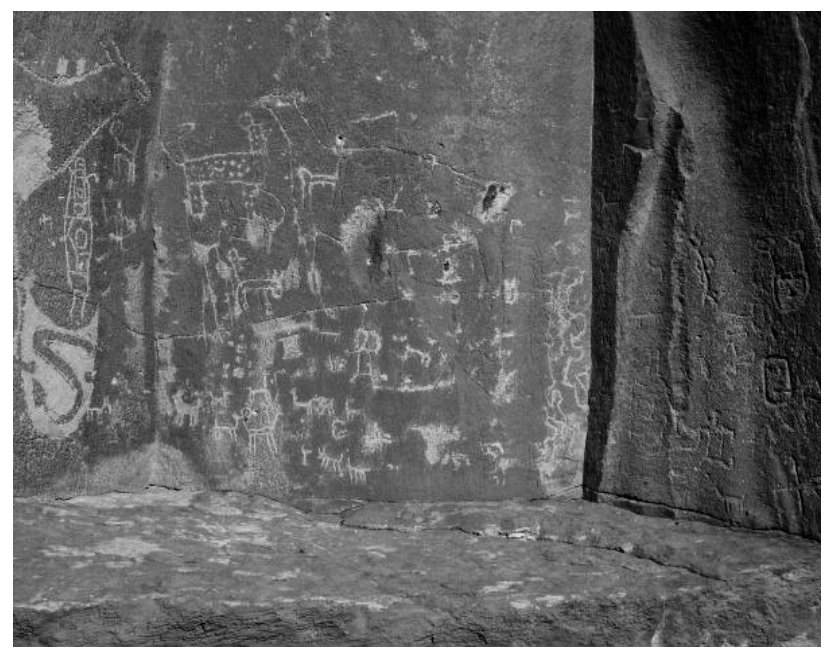

Figura 2. Paneles "entronizados" en el sitio Peñas Coloradas 1.2

Figure 2. "Enthroned" panels from Peñas Coloradas 1.2 site.

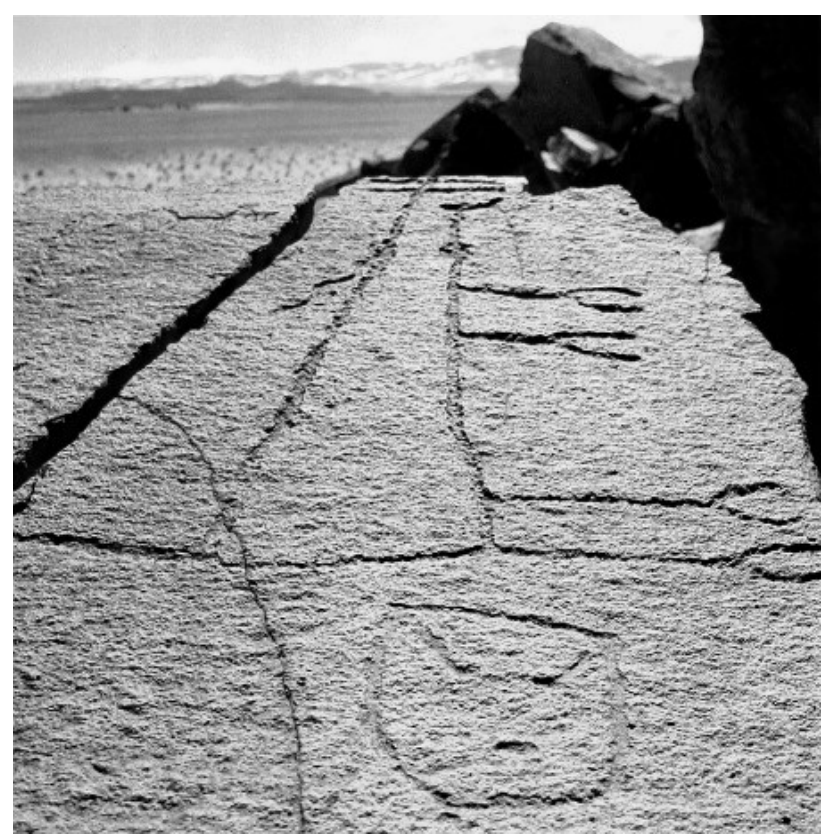

Figura 3. Motivos sobre la UT C5 del sitio Peñas Coloradas 1.2. Emplazado sobre la cara superior de un bloque, queda oculto a menos que se conozca su ubicación (Tomado de Aschero 1999).

Figure 3. Motifs on UT C5 from Peñas Coloradas 1.2 site. Placed on the superior side of a block, it remains hidden to those ignorants of its location (Taken from Aschero 1999).

de la técnica del grabado en relación a los momentos anteriores, aunque en el sector de las Quebradas de Altura (vinculado principalmente con actividades de caza de acuerdo a la información contextual) el predominio de los motivos pintados es muy marcado. De esta manera, y a modo hipotético, podemos sugerir que durante este proceso transicional, repleto de idas y vueltas y nunca entendido como un "salto", la convivencia entre dos modos de subsistencia y vida también se vería replicado en los soportes rupestres. Quizás, en los momentos en que se recurría a la caza como complemento a la producción de alimentos, los productores de arte rupestre elegían mantener las "formas de hacer" más tradicionales, en este caso vinculadas con la pintura y la elección de soportes más reparados, como veremos a continuación. Sin embargo, esta formulación requiere de mayores evidencias materiales para ser sustentada y simplemente la dejamos enunciada de manera hipotética para ser retomada en otro momento.

Así también, en lo que respecta al análisis de la visibilidad de los sitios con arte rupestre de la mRP también se puede apreciar una conducta mixta donde conjugan situaciones de franco acceso visual y promoción de la observación de ciertos motivos (como en los paneles entronizados del sitio Peñas Coloradas 1.2, Figura 2) con otras de marcado "ocultamiento" utilizando soportes de campo visual restringido (ver Figura 3, también del sitio Peñas Coloradas 1.2 pero ocupando una cara oculta del bloque rocoso). 
En definitiva, lo que se aprecia para el caso del arte de la $\mathrm{mRP}$ es una variedad de elecciones en respuesta a un mismo problema, el cual se relaciona con las nuevas condiciones socioeconómicas y las situaciones de riesgo que la circunscripción y el conflicto por los espacios productivos traían aparejadas, frente a las cuales el arte rupestre (y sus diferentes expresiones sitio a sitio, quebrada a quebrada) ofrecía distintas soluciones (Aschero 1999, 2006).

\section{Modalidad Peñas Coloradas}

Durante este periodo, la consolidación de la producción de alimentos como la estrategia de subsistencia fundamental para las poblaciones antofagasteñas ya era prácticamente completa, aunque siempre con el componente de la caza y la recolección como un aditamento complementario (Escola 2002; Olivera 1998). Como veremos en la Discusión, creemos que este componente contextual no determinó la producción rupestre sino que fue cambiando junto con ella en vinculación con modificaciones apreciadas en las más diversas esferas del accionar humano.

Los motivos correspondientes a esta modalidad estilística alcanzan el 51,14\% (381/745) de la muestra total analizada y fueron relevados en 16 de los 22 sitios considerados. Es durante la $\mathrm{MPC}$ que se termina de concretar la tendencia principal que da origen a nuestra investigación, la relacionada con la reversión en lo que respecta a la elección de las técnicas de producción. Los grabados aparecen de manera muy evidente como la técnica más utilizada siendo que el 98.95\% ( $\mathrm{N}=377)$ de los motivos asignables a esta modalidad fueron ejecutados mediante esta técnica, y sólo el $1.05 \%(\mathrm{~N}=4)$ restante corresponde a pinturas ${ }^{3}$. En lo que respecta a la elección de elementos a ser representados se mantiene la tendencia apreciada, donde el 55.38\% ( $\mathrm{N}=211)$ de los motivos corresponde a figurativos, un $35.7 \%$ $(\mathrm{N}=136)$ a no figurativos y el restante $8.92 \%(\mathrm{~N}=34)$ a indeterminados.

La elección de emplazamientos marca una fuerte predominancia de los Sectores Intermedios como espacios en donde plasmar el arte rupestre ya que el 75\% ( $\mathrm{N}=12)$ de los sitios y $84.51 \%(\mathrm{~N}=322)$ de los motivos asignables a la mPC fueron relevados allí. Se identifica también una preferencia por la elección de espacios abiertos que podrían propiciar la observación del arte rupestre desde mayores distancias, sumando evidencias así de un arte de

\footnotetext{
${ }^{3}$ Los datos en relación a esta modalidad estilística no contemplan al sitio Cc1A ya que este no cuenta aún con un informe cuali-cuantitativo definitivo del conjunto rupestre. Es por ello que sólo brindamos información sobre la mayor o menor presencia relativa de ambas técnicas de producción en este sitio en particular. Sí podemos afirmar que los motivos pintados siguen presentándose en este sitio como los más numerosos dentro del conjunto, lo cual nos permite sostener la tendencia diferencial apreciada en este sitio respecto al resto de los considerados aquí.
}

Porcentajes de Elección de Técnicas de Producción del Arte Rupestre

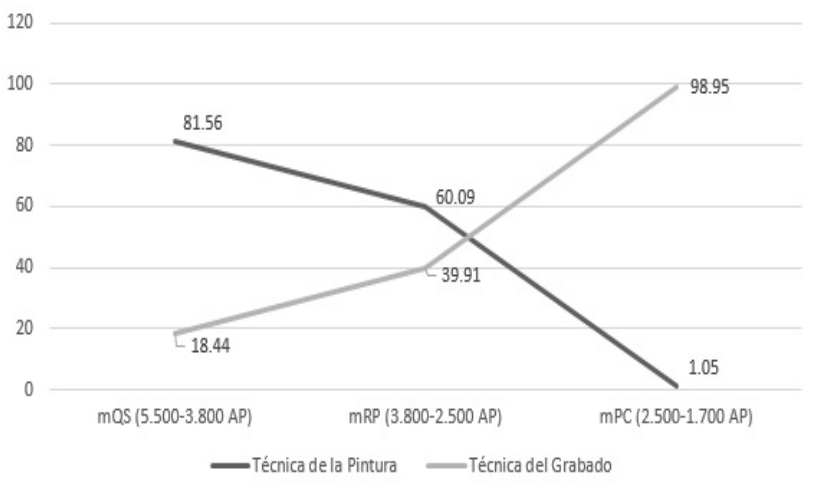

Figura 4. Gráfico de representación de los porcentajes de elección de las diferentes técnicas de producción en ANS (5500-1500 AP)

Figure 4. Graphic depicting the percentages of the different production techniques chosen in ANS (5500-1500 BP).

carácter más público. Un poco más del 87\% (14/16) de los sitios con motivos correspondientes a esta modalidad estilística comparten la utilización de soportes que no presentan reparo (en la forma de farallones ignimbríticos, bloques expuestos o planchadas horizontales).

Un último dato interesante a remarcar, es que para el caso de los sitios utilizados por la mPC, 11 de los 16 (68.75\%) inauguran espacios de interacción o, dicho de otra manera, utilizan espacios y/o paneles que no habían sido elegidos en momentos previos dándose, de manera consecuente, la ausencia de representaciones de modalidades estilísticas anteriores. A su vez, estos sitios agrupan 329 de los 381 motivos correspondientes a esta modalidad -es decir el 86.35\%-, implicando que la elección de espacios nuevos en los cuales ejecutar representaciones rupestres habría sido una tendencia bastante establecida durante estos momentos. La marcada preferencia por la identificación social de nuevos espacios mediante el arte rupestre puede estar relacionada con el aumento de la densidad poblacional y sus consecuentes resultados vinculados con la fisión de grupos y la necesidad de apropiación de nuevos sectores en el paisaje (Aschero 2006).

\section{Discusión sobre 4.000 años de arte rupestre en ans}

Las tendencias relacionadas con la producción rupestre fueron cambiando en el marco de un proceso que ha sido denominado por otros investigadores como de "cambios en la continuidad" (Aschero y Hocsman 2011). Así, el arte rupestre de ANS debe ser comprendido en vinculación con el resto de las esferas del accionar humano que también se vieron sujetas a cambios durante este lapso. Consideramos que esta evaluación contextual amplia es la manera más adecuada para poder acercarnos a 
comprender en su justa medida cualquier materialidad abordada.

Las modificaciones identificadas en el arte rupestre de los aproximadamente 4.000 años analizados abarcan distintos aspectos de su producción, en particular lo referido a las técnicas más utilizadas en cada modalidad estilística para la realización de los motivos. Sin embargo, esa primera variable analizada derivó en la identificación de otras tendencias como la elección de emplazamientos, los tipos de mensajes a ser transmitidos y el público al cual estaban dirigidos éstos.

Por ejemplo, en la Figura 4 podemos ver que las curvas graficando los porcentajes de representación de ambas técnicas de producción rupestre a lo largo del tiempo muestran un comportamiento prácticamente espejado, con una elección mayoritaria de la pintura durante los primeros momentos pero decreciente en el tiempo hasta llegar a una situación de máxima representación del grabado durante la última modalidad estilística abordada.

No sólo nos interesa remarcar esta tendencia y señalar que el "punto de quiebre" se dio justamente durante el nudo del proceso transicional sino que, siguiendo la propuesta de Fiore (2006), hemos intentado vincular la información obtenida con los costos de producción del arte rupestre y los cuatro factores relacionados con las técnicas de producción que en definitiva pudieron haber influido sobre las frecuencias de ejecución de pinturas y grabados rupestres (cantidad de cadenas operativas, disponibilidad de materias primas, dureza de los soportes y perdurabilidad relativa de cada técnica). Cada uno de ellos es discutido brevemente a continuación teniendo en cuenta la información general y la particular de la microrregión:
- A pesar de no haberse realizado análisis particulares en ANS, los trabajos de diversos investigadores (Aschero 1988; Fiore 2006; Méndez Melgar 2007, entre otros) en relación a la cantidad de cadenas operativas permite identificar a la pintura como más costosa que el grabado. - La información disponible, aunque fragmentaria aún, sobre disponibilidad de materias primas pigmentarias para la manufactura de pinturas no nos permite conjeturar una situación de escasez, por lo que este no habría sido un factor determinante al menos para el caso de la microrregión. Si podrían haber existido momentos donde la disputa territorial pudo haber incidido en el acceso a materias primas, por ejemplo, pero esta es una línea de investigación que aún se encuentra en etapas preliminares.

- La totalidad de los motivos rupestres analizados en este trabajo fueron realizados sobre soportes de ignimbrita. Así, al considerar la dureza de los soportes como factor, en ANS estos no habrían estado funcionando como limitantes para la producción rupestre. Es más, en algunos casos las características de la ignimbrita han sido mencionadas, por algunos autores, como propicias para la ejecución de grabados rupestres (Álvarez y Fiore 1995).

- En lo que respecta a la perdurabilidad relativa de cada técnica, siguiendo a Rosenfeld (1988) podemos decir que los grabados tienden a ser más resistentes al deterioro que las pinturas.

Este breve resumen nos permite, a los fines de este trabajo, identificar a la producción de pinturas rupestres como más costosa en términos económicos que la producción de grabados, hipotetizando que la expeditividad de esta última habría sido una característica favorecida al momento de tomar decisiones tecnológicas. Entendemos la necesidad de no tomar esta información

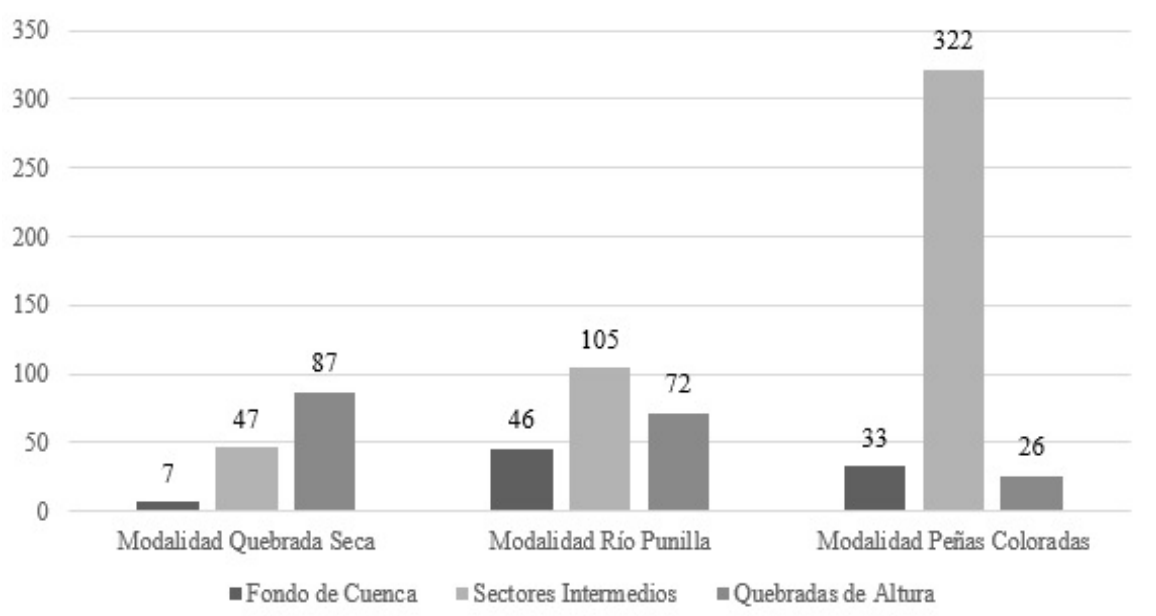

Figura 5. Gráfico de vinculación entre cantidad de motivos y su emplazamiento dentro de ANS para cada modalidad estilística.

Figure 5. Graphic depicting the link between quantity of motifs and their location in ANS for each stylistic modality. como determinista, sino más bien de aprovecharla en la evaluación general de los diversos factores que pudieron haber funcionado como condicionantes de la producción rupestre.

Sin embargo, es interesante destacar que un proceso similar fue documentado durante este mismo lapso pero en relación a la manufactura de artefactos líticos. El proceso de transición hacia la producción de alimentos no sólo implicó una modificación en el modo de subsistencia, sino que las evidencias indican que el cambio entre una economía de base extractiva y una de base productiva trajo aparejada la diversificación de tareas y un consecuente aumento del tiempo 
que debía destinarse a éstas. Una respuesta frente a esta coyuntura fue la de minimizar el tiempo invertido en la manufactura de determinados objetos, situación que ha sido abordada principalmente desde los artefactos líticos (Escola 2004; Hocsman 2006) un componente tecnológico que, durante momentos agro-pastoriles tempranos se caracteriza por "la expeditividad, es decir, en una planificación orientada a minimizar el esfuerzo que pudiera invertirse en la producción de instrumentos" (Escola 2004: 94).

Otra tendencia identificada en el largo plazo es el cambio en el emplazamiento de los sitios con arte rupestre en la microrregión. Como podemos apreciar en la Figura 5, mientras que durante la mQS el sector más utilizado para la representación de motivos fueron las Quebradas de Altura, durante la mRP pero más específicamente para el caso de la mPC, el eje de comunicación viró hacia los Sectores Intermedios. Hemos vinculado esta situación con las modificaciones apreciadas en el sistema de subsistencia principal durante cada uno de los momentos. De esta manera, si las Quebradas de Alturas constituyeron los espacios más adecuados para la instalación de puestos de caza (Aschero y Martínez 2001), fueron los Sectores Intermedios los más aptos para las tareas vinculadas con la producción agrícola-pastoril ya que "en ellos se ubican tierras aptas para terrenos de cultivos, si bien no de gran extensión, excelentes forrajes y agua disponible durante todo el año" (Olivera y Podestá 1993: 97).

Otra de las tendencias remarcables dentro del lapso en cuestión es la relacionada con los tipos de elementos representados durante cada una de las modalidades estilísticas analizadas. Así, analizando la información obtenida pudimos determinar un cambio desde un mayor porcentaje de elementos no figurativos durante los primeros momentos de la secuencia abordada hacia la elección cada vez más marcada de elementos figurativos. Como vimos en el apartado de Resultados, para el caso de la primera modalidad analizada, la mQS, los datos porcentuales indican que los elementos no figurativos representan el 73.05\% (103/141) de la muestra. Para las modalidades estilísticas posteriores los porcentajes de elementos no figurativos decrecen de manera significativa, con un $21.08 \%$ para la mRP (47/223) y un $35.69 \%$ para la mPC (136/381).

Ambas tendencias -énfasis cada vez mayor en la ocupación de los Sectores Intermedios y aumento en la representación de motivos figurativos- pueden interpretarse en relación a la necesidad de resolver las disputas por el acceso a los espacios productivos (Martel 2006), recurriendo tanto a la ocupación efectiva como a determinados motivos para demarcar, territorial e identitariamente, dichos espacios.

Dicho esto, a pesar de haber optado por analizar los cambios observados en el arte rupestre desde el marco de la transición hacia la producción de alimentos, consideramos que esta decisión sólo es una de las tantas posibles y que los resultados obtenidos no deben ser vinculados únicamente con la esfera de lo económico. En este sentido, nuestra búsqueda de distintas vías de interpretación nos ha llevado a considerar otro posible factor ligado a la elección técnica: nos referimos a la significación de los motivos.

Existen tres clases de motivos que hacen su aparición durante el último lapso analizado, el correspondiente a la mPC, y cuya significación pareciera -a priori- estar ligada con la técnica de ejecución. Nos referimos a tres motivos que pueden ser comprendidos como marcadores, territoriales e identitarios respectivamente: las "maquetas" (Aschero et al. 2009; Martel 2006) por un lado y, por el otro, los "cartuchos" (Aschero et al. 2006) y "máscaras" (Aschero 1999).

La ideología, haciendo referencia aquí a la forma en cómo captamos al mundo, nos lleva a pensar en la manera que esta forma de captar el mundo puede condicionar la ejecución de ciertos motivos -favoreciendo la utilización de la técnica del grabado- debido a que la significación de los mismos se asocie con la piedra en sí y con ciertas concepciones andinas (huacas y huauquis). La siguiente cita muestra la manera en que estos conceptos podrían estar relacionándose: "los estudios etnográficos señalan la importancia del doble de la persona en imágenes modeladas o huauqui y en piedras que, por su tamaño y forma, se cree que contienen la potencia del antecesor muerto (monolitos o huancas)" (Aschero 1999: 113, el resaltado es del original), analogía que lleva a este autor a interpretar a los mascariformes como una forma de huauqui.

Aquí intentamos ir un paso más allá y plantear que la relación no se limita a una de orden conceptual sino que también responde a una de orden material, en donde el grabado funciona como una forma de plasmar ese huauqui en la misma roca y no sobre ella (como en el caso de la pintura). La técnica extractiva del grabado permite que aquello que vaya a ser representado lo haga siendo parte del mismo soporte y donde la misma técnica de producción implica el accionar de la piedra sobre la piedra, y no nos referimos a la piedra geológica inanimada sino la piedra como agente que puede incluso contener la esencia de personas ya físicamente desaparecidas -pero lejos de estar muertas- como vimos en la cita.

Por otra parte, creemos que más allá de que los motivos mascariformes sean los que más se adecúen a este esquema aquí planteado, para el caso de las maquetas y los cartuchos se puede sostener una situación similar, sin descartar que en el futuro podamos ampliar el repertorio de motivos cuya significación se pueda vincular con la técnica de producción, sea el grabado o la pintura. En relación a las "maquetas", o esquemas hidrotécnicos, se ha propuesto una vinculación con el control y manejo del agua (Martel 2006) y, su ejecución -generalmente- sobre 
planos inclinados, hace que el vertido del agua sobre el motivo sirva como un modelo a escala de estas posibles "representaciones esquematizadas de sistemas de regadio" (Aschero et al. 2009:260). Teniendo en cuenta estos datos, podemos apreciar cómo el grabado de estos motivos se habría convertido en "necesario" para poder mostrar (y percibir) su verdadera significación.

En el caso de los cartuchos, creemos que su funcionalidad como marcadores identitarios también podría haber requerido de una técnica de ejecución como el grabado para reforzar el mensaje o la información transmitida, una técnica cuya perdurabilidad es mayor no sólo frente a las inclemencias climáticas sino también frente a un posible intento de obliteración intencional. Así, estaríamos en presencia de un accionar intencionado de recurrir a un tipo de técnica de ejecución para la representación de ciertos motivos, una vinculación directa entre significación y producción que, por el momento, no hemos detectado para otros tipos de motivos.

La decisión de plasmar estos motivos sólo recurriendo al grabado (en ningún caso se han identificado estas clases de motivos pintados), nos lleva a buscar alternativas para entender el porqué de tal decisión. Aunque por el momento estas consideraciones figuren principalmente como ideas a seguir siendo desarrolladas, creemos que la búsqueda constante de vías de interpretación alternativas es un paso necesario en la consolidación del abordaje aquí propuesto.

\section{Consideraciones finales}

Comenzamos esta investigación con un objetivo en mente, el de analizar los cambios apreciados en las técnicas de producción del arte rupestre y cómo éstos se relacionaron con el proceso transicional en cuestión. Más allá de los análisis porcentuales y gráficos de tendencias, lo que podemos decir es que el arte rupestre de Antofagasta de la Sierra ha demostrado ser una materialidad sumamente eficaz para analizar (determinadas) conductas sociales de los pobladores de la microrregión en el largo plazo.

La consideración del proceso transicional como un todo nos permitió observar la manera en que los cambios en la producción rupestre se desarrollaban en paralelo a los cambios socio-culturales de las más diversas índoles. La incorporación de nuevas estrategias de subsistencia funcionó como un marco para la acción dentro del cual la técnica del grabado apareció como una novedad tecnológica para la comunicación visual en algún momento entre el 5.500 y 3.800 AP. De allí en adelante son diversos factores los que entran al terreno de juego y desempeñan distintos roles en la producción rupestre: contextos donde la demarcación, (re)significación y segmentación de nuevos espacios se hacían necesarias; apelación a las ventajas económicas expresadas en términos de costos de producción; formas de hacer variables; ideologías cambiantes. Así, de manera gradual al igual que el resto de los cambios registrados en la microrregión, los productores del arte rupestre comenzaron a inclinarse por elegir a la técnica del grabado cada vez con mayor frecuencia.

Invirtiendo la posición desde la cual miramos y evitando aproximarnos al arte rupestre entendiéndolo como resultado del resto de los cambios socio-culturales, sino como parte fundamental y trascendental de los mismos, un aspecto a destacar es la posibilidad de que la producción rupestre y su rol en la demarcación de nuevos espacios hayan desempeñado un papel fundamental en la transición hacia la producción de alimentos. Así, los efectos sociales jalonados por esta materialidad pudieron funcionar como un elemento crucial para la efectivización de la transición desde un modo cazador-recolector hacia uno agro-pastoril en la microrregión de ANS.

Tanto la persistencia como las tasas de producción crecientes a lo largo del tiempo de los motivos ejecutados mediante la técnica del grabado, son interpretadas como indicadores de la eficiencia de esta técnica de producción. Si consideramos que la pintura y el grabado son igualmente eficaces comunicativamente, podemos concluir que el grabado presenta mayores ventajas para su producción (implica menos cadenas operativas y menos tiempo), situación que pudo haber sido valorada al momento de elegir entre una u otra técnica. Consideramos también que los nuevos requerimientos de demarcación e identificación social de los espacios productivos y de habitación, los cuales fueron profundizándose con el paso del tiempo, fueron factores con implicancia sobre la producción rupestre durante el proceso transicional, factibles de ser observados y analizados mediante las tendencias de utilización de emplazamientos, el concepto de visibilidad e incluso a través de las perdurabilidades relativas de las técnicas de producción.

Sin embargo, ciertas observaciones realizadas en el curso de la investigación llevan a pensar que no es sólo la posible eficiencia productiva y mejor adecuación a los requerimientos socio-culturales lo que termina por posicionar al grabado como la técnica más utilizada, sino que otros factores, tales como la ideología, también cumplen un rol fundamental.

El establecimiento de la técnica del grabado como la más utilizada durante el proceso transicional no puede (ni debe) ser explicado únicamente desde la exhibición de datos porcentuales y apelando a una ventaja económica de la técnica per se, sino que es la consideración de la dimensión histórica y, por sobre todo, social de los cambios -las elecciones realizadas por persona/s particulares involucradas en redes de relaciones con otras personas- la que permite ampliar el horizonte de posibles interpretaciones y la formulación de nuevas preguntas. Nuestro objetivo fue el de ir más allá de la tesela individual 
del mosaico (el arte rupestre) y tratar de apreciar la imagen completa formada por cada una de ellas (la sociedad).

La conclusión de que los contextos socio-culturales del proceso transicional conllevaron modificaciones en el accionar de los pobladores antofagasteños puede desprenderse del análisis de diversas temáticas arqueológicas, sin embargo, que el grabado haya sido elegido por sus menores costos de producción o por su capacidad de aportar una mayor carga de significación a la representación de determinados motivos, es algo que solamente podemos abordar y dilucidar desde las investigaciones de arte rupestre. Tales investigaciones requieren, por supuesto, que el enfoque esté puesto sobre el entramado de relaciones y materialidades asociadas al arte.

Tanto las variables analizadas como la metodología empleada no son propuestas como la única vía de abordaje, sino como un primer intento de comenzar a delinear interpretaciones que tengan en cuenta a los contextos sociales cambiantes como integradores de múltiples experiencias particulares.

San Miguel de Tucumán, 25 de octubre 2017

\section{Agradecimientos}

Este trabajo aparece como resultado, extensión y refinamiento de mi Tesis de Grado, la cual fue desarrollada contando con la ayuda de una Beca de Investigación otorgada por la Secretaría de Ciencia y Técnica de la Universidad Nacional de Tucumán (CIUNT). Además, el marco de investigación llegó de la mano de la participación en el proyecto PIUNT G503 dirigido por el Lic. Carlos Aschero, y el proyecto PICT 2013-1703 dirigido por el Dr. Salomón Hocsman.

A Álvaro Martel por su constante guía, no sólo en esta publicación sino a lo largo de mi formación. A Carlos Aschero, Mercedes Podestá, Dánae Fiore y muchos otros investigadores, por ir sentando bases sobre las cuales se hace posible construir. A Vanesa Juarez por las revisiones preliminares y valiosos comentarios. No obstante, todo lo aquí expresado es de mi exclusiva responsabilidad.

\section{Bibliografía}

Álvarez, M. y Fiore, D. (1995). Recreando imágenes: diseño de experimentación acerca de las técnicas y los artefactos para realizar grabados de arte rupestre. Cuadernos del INAPL, 16, 215-239.

Aschero, C. A. (1983-1985). Pinturas rupestres en asentamientos cazadores-recolectores. Dos casos de análisis aplicando difracción de rayos-X. Cuadernos del Instituto Nacional de Antropología, 10, 51-69.

Aschero, C. A. (1988). Pinturas rupestres, actividades y recursos naturales; un encuadre arqueológico. En H. Yacobaccio, Arqueología Contemporánea Argentina. Actualidad y Perspectivas (págs. 109-142). Buenos Aires: Ediciones Búsqueda.
Aschero, C. A. (1996). Arte y Arqueología: una visión desde la Puna argentina. Chungara, 28(1-2), 175-197.

Aschero, C. A. (1999). El arte rupestre del Desierto Puneño y el Noroeste Argentino. En J. Berenguer y F. Gallardo, Arte Rupestre en los Andes de Capricornio (págs. 97-135). Santiago de Chile: Museo Chileno de Arte Precolombino.

Aschero, C. A. (2006). De cazadores y pastores. El arte rupestre de la Modalidad Río Punilla en Antofagasta de la Sierra y la cuestión de la complejidad en la Puna Meridional argentina. En D. Fiore y M. Podestá, Tramas en la Piedra. Producción y Usos del Arte Rupestre (págs. 103-140). Buenos Aires: Sociedad Argentina de Antropología, AINA, WAC.

Aschero, C. A. y Hocsman, S. (2011). Arqueología de las ocupaciones cazadoras-recolectoras de fines del Holoceno Medio de Antofagasta de la Sierra (Puna meridional argentina). Chungara, 43(1), 393-411.

Aschero, C. A., Izeta, A. D. y Hocsman, S. (2014). New Data on South American Camelid Bone Size Changes during MiddleLate Holocene Transition: Osteometry at Peñas Chicas 1.5 (Antofagasta de la Sierra, Argentinian Puna). International Journal of Osteoarchaeology, 24, 492-504.

Aschero, C. A. y Martel, A. R. (2003-2005). El arte rupestre de Curuto-5. Antofagasta de la Sierra (Catamarca). Cuadernos del INAPL, 20, 47-72.

Aschero, C. A., Martel, A. R. y López Campeny, S. M. (2006). Tramas en la piedra: rectángulos con diseños geométricos en Antofagasta de la Sierra (Puna meridional argentina). En D. Fiore y M. Podestá, Tramas en la Piedra. Producción y Usos del Arte Rupestre (págs. 141-156). Buenos Aires: Sociedad Argentina de Antropología, AINA, WAC.

Aschero, C. A., Martel, A. R. y López Campeny, S. M. (2009). El sonido del agua...arte rupestre y actividades productivas. El caso de Antofagasta de la Sierra. Noroeste Argentino. En M. Sepúlveda, J. Chacama y L. Briones, Crónicas sobre la piedra. Arte Rupestre de las Américas (págs. 257-270). Arica: Universidad de Tarapacá.

Aschero, C. A. y Martínez, J. G. (2001). Técnicas de caza en Antofagasta de la Sierra, Puna Meridional argentina. Relaciones de la Sociedad Argentina de Antropología, XXVI, 215-241.

Aschero, C. A. y Podestá, M. M. (1986). El arte rupestre en asentamientos precerámicos de la Puna Argentina. Runa, XVI, 29-57.

Babot, M. P. (2004). Tecnología y utilización de artefactos de molienda en el Noroeste prehispánico. Tesis de Doctorado Inédita. San Miguel de Tucumán, Facultad de Ciencias Naturales e Instituto Miguel Lillo: Universidad Nacional de Tucumán.

Babot, M. P. (2009). La cocina, el taller y el ritual: explorando las trayectorias del procesamiento vegetal en el Noroeste argentino. Darwiniana, 47(1), 7-30.

Babot, M. P. (2011). Cazadores-recolectores de los Andes Centro-Sur y procesamiento vegetal. Una discusión desde la Puna Meridional Argentina (ca. 7.000-3.200 AP). Chungara, 43(1), 413-432. 
Babot, M. P. (2014). Movilidad y artefactos de molienda en Antofagasta de la Sierra, Puna Meridional Argentina (ca. 6.5001.100 años AP). En P. Escola y S. Hocsman, Artefactos Líticos, Movilidad y Funcionalidad de Sitios: Problemas y Perspectivas (págs. 25-39). Oxford: British Archaeological Reports.

Barnard, A. (2001). Los pueblos cazadores recolectores. Buenos Aires, Argentina: Fundación Navarro Viola.

Berenguer, J. (1995). El arte rupestre de Taira dentro de los problemas de la arqueología atacameña. Chungara, 27(1), 7-43.

Cremonte, M. B., Botto, I. L., Canafoglia, M., Hocsman, S., Rodríguez, M., Aschero, C. A. y Grazzoli, D. (2010). Una nueva tecnología en cazadores-recolectores transicionales de la Puna argentina. Caracterización de un recipiente con fibra vegetal. En S. Bertolino, R. Cattaneo y A. D. Izeta, La Arqueometría en Argentina y Latinoamérica (págs. 43-48). Córdoba, Argentina: Editorial de la Facultad de Filosofía y Humanidades.

Criado Boado, F. (1993). Límites y posibilidades de la arqueología del paisaje. SPAL Revista de Prehistoria y Arqueología, 2, 9-55.

Escola, P. S. (2002). Caza y pastoralismo: un reaseguro para la subsistencia. Relaciones de la Sociedad Argentina de Antropología, 27, 233-245.

Escola, P. S. (2004). Tecnología lítica y sociedades agro-pastoriles tempranas. En A. Acosta, D. Loponte, \& M. Ramos, Temas de Arqueología, Análisis Lítico (págs. 59-100). Buenos Aires, Argentina: Universidad Nacional de Luján.

Escola, P. S., López Campeny, S. M., Martel, A. R., Romano, A. S., Hocsman, S. y Somonte, C. (2013). Re-conociendo un espacio. Prospecciones en la Quebrada de Miriguaca (Antofagasta de la Sierra, Catamarca). ANDES (online), 24(2).

Fiore, D. (2006). Poblamiento de imágenes: arte rupestre y colonización de la Patagonia. Variabilidad y ritmos de cambio en tiempo y espacio. En D. Fiore y M. Podestá, Tramas en la Piedra. Producción y Usos del Arte Rupestre (págs. 43-61). Buenos Aires, Argentina: Sociedad Argentina de Antropología, AINA, WAC.

Fiore, D. (2007). The economic side of rock art. Concepts on the production of visual images. Rock Art Research, 24(2), 149-160.

Foucault, M. (2001). Un diálogo sobre el poder y otras conversaciones. Buenos Aires, Argentina: Alianza Editorial.

Gallardo, F. (2001). Arte rupestre y emplazamiento durante el Formativo Temprano en la Cuenca del Río Salado (Desierto de Atacama, Norte de Chile). Boletín del Museo Chileno de Arte Precolombino, 8, 83-97.

Gallardo, F. (2004). El arte rupestre como ideología: un ensayo acerca de pinturas y grabados en la localidad del Río Salado (Desierto de Atacama, Norte de Chile). Chungara, 36(Especial Tomo I), 427-440.

Gallardo, F., Sinclaire, C. y Silva, C. (1999). Arte rupestre, emplazamiento y paisaje en la cordillera del Desierto de Atacama. En J. Berenguer y F. Gallardo, Arte Rupestre en los Andes de Capricornio (págs. 57-96). Santiago, Chile: Museo Chileno de Arte Precolombino.
Hocsman, S. (2002). ¿Cazadores-recolectores complejos en la Puna meridional argentina? Entrelazando evidencias del registro arqueológico de Antofagasta de la Sierra (Catamarca). Relaciones de la Sociedad Argentina de Antropología, 27, 193-214.

Hocsman, S. (2006). Producción lítica, variabilidad y cambio en Antofagasta de la Sierra -ca. 5.500-1.500 AP. Tesis de Doctorado Inédita. La Plata: Facultad de Ciencias Naturales y Museo. Universidad Nacional de La Plata.

Hocsman, S. (2007). Aportes del sitio Peñas Chicas 1.3 a la arqueología de fines del Holoceno Medio de Antofagasta de la Sierra (Catamarca, Argentina). Cazadores-Recolectores del Cono Sur, 2, 167-189.

Hocsman, S. (2010). Cambios en las puntas de proyectil durante la transición de cazadores-recolectores a sociedades agro-pastoriles en Antofagasta de la Sierra (Puna argentina). Arqueología, 16, 59-86.

Hocsman, S. y Babot, M. P. (2018). La transición de cazadoresrecolectores a sociedades agro-pastoriles en Antofagasta de la Sierra (Puna de Catamarca, Argentina): Pespectivas desde la agencia y las prácticas. Chungara, 50(1), 51-70.

Hocsman, S., Babot, M. P., Cremonte, M. B., Aguire, M., Gerónimo, A. y Calisaya, A. (2012). Sobre límites difusos: hacia el "Formativo" en la Puna argentina y su borde oriental. Arqueología del Periodo Formativo en Argentina. Un encuentro para integrar áreas y sub-disciplinas, revisar significados y potenciar el impacto de las investigaciones en curso. Tafí del Valle, Tucumán.

Lavallée, D. (2006). Secuencias y consecuencias de algunos procesos de neolitización en los Andes Centrales. Estudios Atacameños, 32, 35-41.

Lazzari, M. (1999). Distancia, espacio y negociaciones tensas: el intercambio de objetos en arqueología. En A. Zarankin y F. Acuto, Sed non Satiata. Teoría Social en Arqueología Latinoamericana Contemporánea (págs. 117-151). Buenos Aires, Argentina: Ediciones El Tridente.

Lemonnier, P. (1986). The Study of Material Culture Today: Towards an Anthropology of Technical Systems. Journal of Anthropological Archaeology, 5, 147-186.

Martel, A. R. (2006). Arte rupestre y espacios productivos en el Formativo: Antofagasta de la Sierra (Puna meridional argentina). En D. Fiore y M. Podestá, Tramas en la Piedra. Producción y Usos del Arte Rupestre (págs. 157-167). Buenos Aires, Argentina: Sociedad Argentina de Antropología, AINA, WAC.

Martel, A. R. (2009). Arte rupestre: construcción y significación del espacio en la Puna meridional argentina (Antofagasta de la Sierra, Catamarca). En M. Sepúlveda, J. Chacama y L. Briones, Crónicas sobre la piedra. Arte Rupestre de Las Américas (págs. 271-280). Arica, Chile: Universidad de Tarapacá.

Martel, A. R. y Escola, P. S. (2011). Bloques y arte rupestre en la Quebrada de Miriguaca (Depto. de Antofagasta de la Sierra, Catamarca, Argentina). Boletín de la SIARB, 25, 84-92. 
Martel, A. R., Rodríguez Curletto, S. y Del Bel, E. (2012). Arte rupestre y espacios de memoria: las representaciones del sitio Confluencia (Antofagasta de la Sierra, Catamarca, Argentina). Revista Chilena de Antropología, 25(1), 121-162.

Martínez, J. G., Mondini, M., Pintar, E. y Reigadas, M. C. (2010). Cazadores-recolectores tempranos en la Puna meridional argentina: Avances en su estudio en Antofagasta de la Sierra (Pleistoceno Final - Holoceno Temprano/Medio). XVII Congreso Nacional de Arqueología Argentina, Tomo IV, págs. 1691-1696. Mendoza.

Méndez Melgar, C. (2007). Cadenas operativas en la manufactura de arte rupestre: un estudio de caso en El Mauro, valle cordillerano del Norte Semiárido de Chile. Intersecciones en Antropología, 9, 145-155.

Núñez, L. (1994). Cruzando la cordillera por el norte: Señoríos, caravanas y alianzas. En F. Mena, La Cordillera de los Andes: Ruta de Encuentros (págs. 9-19). Santiago, Chile: Museo Chileno de Arte Precolombino.

Núñez, L., Cartajena, I., Carrasco, C., de Souza, P. y Grosjean, M. (2006). Emergencia de comunidades pastoralistas formativas en el sureste de la Puna de Atacama. Estudios Atacameños, 32, 93-117.

Núñez, L. y Santoro, C. (2011). El tránsito Arcaico-Formativo en la circumpuna y valles occidentales del Centro Sur Andino: hacia los cambios neolíticos. Chungara, 43(1), 487-530.

Oliszewski, N., Martínez, J. G., Arréguez, G., Gramajo Bühler, C. M. y Naharro, M. E. (2018). La Transición vista desde los valles intermontanos del Noroeste Argentino: Nuevos datos de la Quebrada de los Corrales (El Infiernillo, Tucumán, Argentina). Chungara, 50(1), 71-86.

Olivera, D. E. (1992). Tecnología y estrategias de adaptación en el Formativo (agro-alfarero temprano) de la Puna meridional argentina. Un caso de estudio: Antofagasta de la Sierra (Pcia. de Catamarca, R.A.). Tesis de Doctorado Inédita. La Plata, Argentina: Facultad de Ciencias Naturales, Universidad Nacional de La Plata.

Olivera, D. E. (1998). Cazadores y Pastores Tempranos de la Puna
Argentina. En S. Ahlgren, A. Muñoz, S. Sjödin y P. Stenborg, Past and Present in Andean Prehistory and Early History (págs. 153-180). Gotenburgo, Suecia: Etnografiska Museer.

Olivera, D. E. y Podestá, M. M. (1993). Los recursos del arte: arte rupestre y sistemas de asentamiento-subsistencia formativos en la Puna meridional argentina. Arqueología, 3, 93-126.

Pfaffenberger, B. (1992). Social Anthropology of Technology. Annual Review of Anthropology, 21, 491-516.

Pintar, E. (2014). Continuidades e hiatos ocupacionales durante el Holoceno Medio en el borde oriental de la Puna Salada, Antofagasta de la Sierra, Argentina. Chungara, 46(1), 51-71.

Podestá, M. M. (1986-1987). Arte rupestre en asentamientos de cazadores-recolectores y agroalfareros en la Puna Sur Argentina: Antofagasta de la Sierra. Relaciones de la Sociedad Argentina de Antropología, 17(1), 241-263.

Reigadas, M. (2000-2002). Innovación tecnológica como factor de cambio en las estrategias económicas. La domesticación animal. Cuadernos del INAPL, 19, 573-597.

Rosenfeld, A. (1998). Rock Art Conservation in Australia. Canberra, Australia: Special Australian Heritage Publication Series 2 .

Schaafsma, P. (1985). Form, Content and Function: Theory and Method in North American Rock Art Studies. Advances in Archaeological Method and Theory, 8, 237-277.

Urquiza, S. V. y Aschero, C. A. (2014). Economía animal a lo largo del Holoceno en la Puna Austral argentina: Alero Punta de la Peña 4. Cuadernos del INAPL - Series Especiales, 2(1), 86-112.

Vergara, F. y Troncoso, A. (2015). Rock art, technique, and technology: an exploratory study of hunther-gatherer and agrarian communities in pre-Hispanic Chile (500 to 1450 CE). Rock Art Research, 32(1), 31-45.

Yacobaccio, H. D. (2001). Cazadores complejos y domesticación de camélidos. En G. Mengoni, D. Olivera, \& H. Yacobaccio, El uso de los camélidos a través del tiempo (págs. 261-282). Buenos Aires, Argentina: Ediciones El Tridente. 